\title{
Assessing the contribution of demand side management to power system flexibility
}

DOI:

10.1109/CDC.2011.6161236

Link to publication record in Manchester Research Explorer

\section{Citation for published version (APA):}

Rosso, A., Ma, J., Kirschen, D. S., \& Ochoa, L. F. (2011). Assessing the contribution of demand side management to power system flexibility. In Proceedings of the IEEE Conference on Decision and Control/Proc IEEE Conf Decis Control (pp. 4361-4365) https://doi.org/10.1109/CDC.2011.6161236

\section{Published in:}

Proceedings of the IEEE Conference on Decision and Control|Proc IEEE Conf Decis Control

\section{Citing this paper}

Please note that where the full-text provided on Manchester Research Explorer is the Author Accepted Manuscript or Proof version this may differ from the final Published version. If citing, it is advised that you check and use the publisher's definitive version.

\section{General rights}

Copyright and moral rights for the publications made accessible in the Research Explorer are retained by the authors and/or other copyright owners and it is a condition of accessing publications that users recognise and abide by the legal requirements associated with these rights.

\section{Takedown policy}

If you believe that this document breaches copyright please refer to the University of Manchester's Takedown Procedures [http://man.ac.uk/04Y6Bo] or contact uml.scholarlycommunications@manchester.ac.uk providing relevant details, so we can investigate your claim.

\section{OPEN ACCESS}




\title{
Assessing the Contribution of Demand Side Management to Power System Flexibility
}

\author{
Angel Rosso, Juan Ma, Student Member, IEEE, \\ Daniel S. Kirschen, Fellow, IEEE, and Luis F. Ochoa, Member, IEEE
}

\begin{abstract}
The increasing penetration of renewable energy sources, particularly wind power, raises concerns about the level of flexibility needed to cope with the inherent variability and uncertainty affecting these sources of energy. Departing from the common conception of providing flexibility using fossil-fuelled generators with fast ramp rates, this paper explores the use of demand-side resources. A technique to optimize the balance between the flexibility provided by fast generating units and the flexibility achievable from demand side management (DSM) is presented. This methodology is based on an extended unit commitment optimization that considers both short- and longterm aspects, i.e. operational and investment costs. The methodology is applied to the IEEE RTS (RTS-96), using actual demand and wind profiles from central Scotland.
\end{abstract}

Index Terms-- Flexibility, demand side management, integration of wind generation, long-term unit commitment, reserve requirements.

\section{INTRODUCTION}

$\mathrm{T}$ HE growth of worldwide electricity consumption, the instability of fossil fuel prices, concerns about security of supply, and environmental issues have driven investment in new low-carbon and renewable generating plants, with wind power being the leading technology. However, wind, sun, tides and waves cannot be controlled to provide energy when it is required by the system. Consequently, the progressive introduction of these technologies requires that more flexibility be provided to cope with their inherent variability. Flexibility is usually provided by generators that have fast start time, high up and down ramping rates, and low minimum up- and down-time. Interconnections with other (flexible) systems represents another conventional solution.

Providing flexibility is expensive because it often involves producing energy with more agile but less efficient generating units or operating plants below their maximum efficiency loading. It is thus important to know how much flexibility is actually needed in a given power system and how much flexibility can be provided in a cost-effective manner by the demand side or using storage technologies.

Achieving an optimal flexible generation portfolio is a problem that has been studied for some time [1]. The

A Rosso, J Ma and L F Ochoa are with the School of Electrical and Electronic Engineering at The University of Manchester, Manchester, UK. (email: angel.rossomateo@postgrad.manchester.ac.uk, juan.ma@postgrad.manchester.ac.uk, luis_ochoa@ieee.org)

D S Kirschen is with the University of Washington, Seattle WA, USA. (email:kirschen@uw.edu) liberalization of the electricity markets has made this issue more complex because it is necessary to take into account regulatory issues when analyzing the flexibility provided by the different participants of the system in order to optimize the corresponding bid strategies [2]. In a context where more renewable generation is being connected, it has also been shown that when the stochastic nature of wind power is taken into account, rolling commitment strategies would lead to improved economic performance because this would reduce the error on the wind predictions [3]. The consequence, however, is a reduced overall utilization of expensive peaking units.

It is common for certain types of large consumers (e.g. refrigeration industry, commercial buildings with large air conditioning systems) to be offered contracts where part of the load can be disconnected occasionally to help the utility reduce operating costs or deal with network constraints. The duration and frequency of these disconnections depends on their technical and economic impact on the industrial or commercial customer. Although beneficial to the system, this type of Demand Side Management (DSM) is limited because of the high value of these loads and hence of the high price that would have to be paid to make them available. For this very reason, an important contribution to DSM schemes is likely to come in the future from residential customers. The integration of real-time monitoring and control of smart appliances, part of the concept behind Smart Grids, will potentially enable DSM schemes resulting in an aggregated effect that will significantly contribute to power system flexibility [4], [5].

Enhancing the ability of demand to respond to price signals can help markets operate more efficiently resulting in less onerous flexibility requirements [6]. The optimal scheduling of DSM during critical price periods, particularly thermal loads, was explored in [7], resulting in a significant reduction in the need for flexible generation units. Using a securityconstrained unit commitment approach, [8] showed that introducing DSM would reduce both load curtailment (and the corresponding losses of profit or comfort) and the need for investments in grid reinforcements.

The interaction between DSM and renewable resources has also being researched in the literature. In [9], two particular ways of managing under floor heating from electrically operated heat pumps are evaluated: for peak shaving, and for charging/discharging following high/low wind periods, respectively. In this case, DSM reduces the number of occasions when peaking units have to be started or wind 
power production has to be curtailed. However, this approach does not optimize the overall operation of the generating units or the generation portfolio. Other strategies such as real time pricing (RTP) have been shown to reduce load curtailment events and the need for additional reserve requirements and hence the cost of wind uncertainty is reduced [10].

Despite the fact that increasing amounts of renewable generation capacity requires more flexible power systems, not enough work has been done to provide reliable estimates of the amount of flexibility needed. Furthermore, it is also important to assess the contribution that DSM might have in future, so that it is possible to establish the benefits and profitability (from the energy suppliers' perspective) of this resource.

The main contribution of this paper is the proposal of a method that is capable of optimizing the generation portfolio taking into account not only the operational costs but also the investment costs. This tool can be used to observe the effect of the introduction of flexible resources such as DSM and assess the impact of inflexible resources such as wind generation.

The rest of this paper is organized as follows. The proposed methodology, including problem formulation and a simple case study is presented in Section II. Section III presents and discusses results based on the IEEE RTS (RTS-96). Section IV draws the conclusions.

\section{METHODOLOGY}

This study is based on a unit commitment (UC), formulated as a mixed integer linear programming (MILP) problem. The UC minimizes the cost of scheduling a portfolio of generators during a given time period. Typically, the horizon is one or two weeks. This classical computation accounts for the running, no-load, start-up and shut-down costs, while considering the technical constraints on the generation units (i.e. limits on generation, ramp rates, and minimum up and down times). Although UC is one of the most used tools to minimize generation costs, it is limited to short-term analysis.

This paper extends the work presented in [11] where the classical UC was extended to analyze all the flexibility constraints and the overall costs during a year. To reduce the computational burden, the year-long horizon is decomposed into four representative weeks corresponding to each season. An additional week representing the worst-case scenario (e.g. an extreme winter week) is also considered. To account for the annual electricity generation, each week is weighted in the objective function by the number of weeks that it represents. In the case of the worst case scenario week, it is assumed that such a situation only happens once every four years, so the impact on the objective function is very low. Table I shows the corresponding weighting factors, totalling 52 weeks.

To avoid incorrect start-up costs, the initial and final conditions for each week must be handled carefully. Since each week is representative of all the weeks of a season, it is reasonable to assume that the status of the units at the beginning of each representative week should be the same as the status of these units at the end of the same week. Fig. 1 illustrates this assumption
TABLE I

WEIGHTING FACTORS - REPRESENTATIVE WEEKS

\begin{tabular}{|l|c|}
\hline Winter week & 16.75 \\
\hline Extreme winter week & 0.25 \\
\hline Spring week & 9 \\
\hline Summer week & 13 \\
\hline Autum week & 13 \\
\hline
\end{tabular}

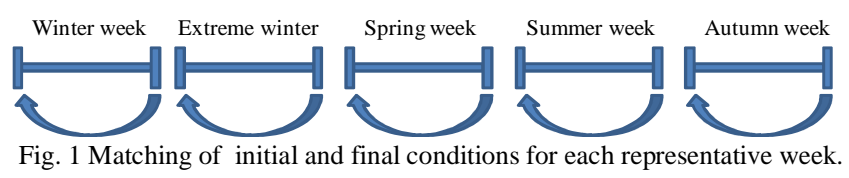

Since our goal is to determine the ideal flexible portfolio and the corresponding investment costs, rather than simply optimizing the capacity of a given type of units (e.g. gas turbines) the model considers a set of units as possible investments and determines the optimal number and type of units that should be added to the system to minimize the sum of the annual operating and investment costs.

DSM is incorporated in the model by allowing part of the load to be curtailed and 'recovered' later in the same day. In other words, the available DSM is a fraction of the hourly demand that can be 'shifted' to be supplied at another time later in the day. This concept is consistent with the expected mode of operation of smart appliances.

\section{A. Problem Formulation}

The objective function (1) minimizes generation costs and the investment costs. The generation cost, $G C(i, t)$, includes the start up, no load, and production cost of each unit. This cost is multiplied by the corresponding weighting factor, $K(w)$, of each representative week. The investment cost, $\operatorname{AIC}(i)$, accounts for the amortized investment cost of the generating units. $e(i)$, is a binary variable that indicates whether a unit $i$ has been selected from the available portfolio of potential investments. The operating cost of a particular generating unit is zero if it has not been selected.

Because investments in wind generation rely heavily on various forms of subsidies or on mandates, they represent more a political than a technical decision. The construction of wind farms are therefore not taken into account in the investment costs of the system.

$\min \left\{\sum_{i=1}^{I}\left(\sum_{w=1}^{w e e k s} K(w) * \sum_{t=t_{0(w)}}^{t_{\text {end }(w)}} G C(i, t)+\operatorname{AIC}(i) * e(i)\right)\right\}$

Equation (2) enforces the power balance constraint between generation, $G(i, t)$, demand, $D(t)$, and the committed aggregated capacity of DSM schemes, $\operatorname{DSM}(t)$ is considered in (2), while Equation (3) enforces the reserve requirements.

$$
D(t)-\operatorname{DSM}(t)=\sum_{i=1}^{I} G(i, t) \forall t \in 1, T
$$

The generators' contribution to reserve is the difference between the maximum power available, $\overline{G(i)}$, and the actual power output, $G(i, t)$, of those units committed, $u_{c}(i, t)$, at 
instant $t$. The reserve-related contribution of DSM schemes is similar to the generation contribution: it is the DSM capacity still available, i.e. $\overline{D S M}-D S M(t)$, where $\overline{D S M}(t)$ is the maximum DSM capacity that can be used at instant $t$.

$$
\begin{gathered}
\sum_{i=1}^{I} u_{c}(i, t) *(\overline{G(i)}-G(i, t))+(\overline{D S M}(t)-D S M(t)) \\
\geq S R(t) \forall t \in 1, T
\end{gathered}
$$

The reserve requirements, $S R(t)$, includes the possible loss of the largest generation unit and a factor that accounts for the uncertainties of wind generation. This reserve constraint has an important effect on the optimal amount of flexibility because it often forces the commitment of peaking units that are expensive to operate but relatively cheap to build.

As mentioned above, there is a maximum DSM capacity at every instant $t$. This limit is modelled as a fraction $P$ of the actual demand, $D(t)$, during that period (4). Equation (5) ensures that energy that is shifted by DSM is recovered during the same day.

$$
\begin{gathered}
-\overline{D S M}(t) \leq \overline{D S M}(t) \leq \overline{D S M}(t) \forall t \in 1, T \\
\overline{D S M}(t)=P * D(t) \\
\sum_{t=t_{0(d)}}^{t_{\text {end }(d)}} D S M(t)=0 \forall d \in 1, \text { Days }
\end{gathered}
$$

Conventional constraints on the operation of the generating units, such as limits on the ramp rates and the minimum working and cooling times are also considered.

\section{B. 24-hour Case Study}

In order to evaluate the performance of the model and understand the impact of DSM on the demand-supply balance, this subsection presents a simple case study for 24 hours. The demand is modelled as a constant value modified by a sinusoid, i.e. $D(t)=250-50 * \sin ((t) * \pi / 12) \quad$ [MW]. This very well known shape makes it easier to visualize the impact of different DSM penetrations on the generation profile. The available DSM capacity is taken as a fraction of the scheduled demand of the corresponding hour. In addition, the committed DSM capacity recovered during the same day in order to mimic the behaviour of price-sensitive smart appliances. In other words, committed DSM capacity is shifted from one period to another during the same day.

$$
\text { TABLE II }
$$

GENERATORS CHARACTERISTICS - TEST CASE

\begin{tabular}{lll} 
Unit & A & B \\
\hline Min Power $(\mathrm{MW})$ & 60 & 60 \\
\hline Power elbow1 $(\mathrm{MW})$ & 236 & 150 \\
\hline Power elbow2 $(\mathrm{MW})$ & 240 & 240 \\
\hline Power elbow3 $(\mathrm{MW})$ & 244 & 360 \\
\hline Max Power $(\mathrm{MW})$ & 400 & 600 \\
\hline Variable Cost 1 $(\$ / \mathrm{MW})$ & 8 & 25 \\
\hline Variable Cost 2 $(\$ / \mathrm{MW})$ & 8.4 & 25.5 \\
\hline Variable Cost 3 $(\$ / \mathrm{MW})$ & 8.8 & 26 \\
\hline Variable Cost 4 $(\$ / \mathrm{MW})$ & 10 & 26.5 \\
\hline No Load Cost $(\$)$ & 200 & 25 \\
\hline Investment Cost $(\mathrm{M} \$)$ & 20 & 10 \\
\hline Ramp Up/Down $(\mathrm{MW} / \mathrm{h})$ & $50 / 200$ & $50 / 60$ \\
\hline Min time Up /Down $(\mathrm{h})$ & $8 / 5$ & $1 / 1$ \\
\hline
\end{tabular}

The generation portfolio consists of only two units: Unit A is a base unit, with a low operating cost and slow ramp rates while Unit B has the opposite characteristics (see Table II).

Fig. 2 clearly shows that with higher penetrations of DSM, the final energy profile flattens. It is important to mention that the piecewise linear approximation of generation costs has an impact on the final shape of the profiles. Since the cost function is a linear approximation, any load point between two elbows of the piecewise linear curve has the same final value on the objective function. Since, this is a demonstration case, the location of the elbows of the piece wise linear approximation was selected so the final profile with no limit on DSM would give a result of a flat profile.

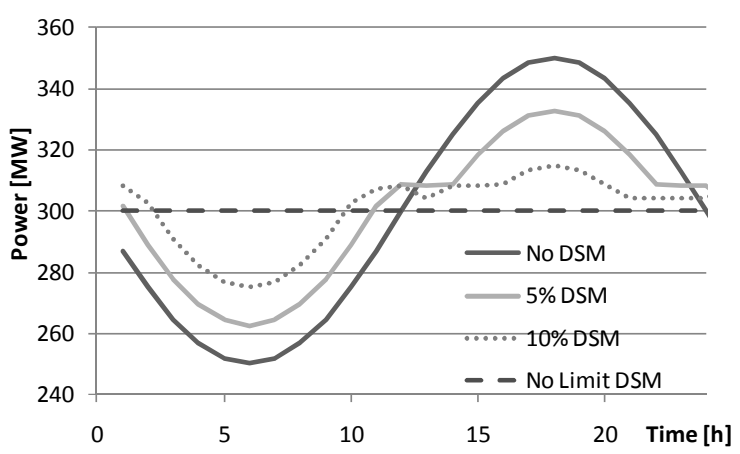

Fig. 2 Progressive impact on the generation profile of DSM.

Since Unit A is cheaper than Unit B, this unit should be committed at its maximum capacity before any other. However, in order to cope with the reserve requirements of the system, Unit B must be synchronized and operated at its technical minimum (Fig 3). DSM could improve the performance of the system reducing the necessity of keeping peaking units online to provide spinning reserves. In systems with a wider portfolio, some of the peaking units would not need to be committed.

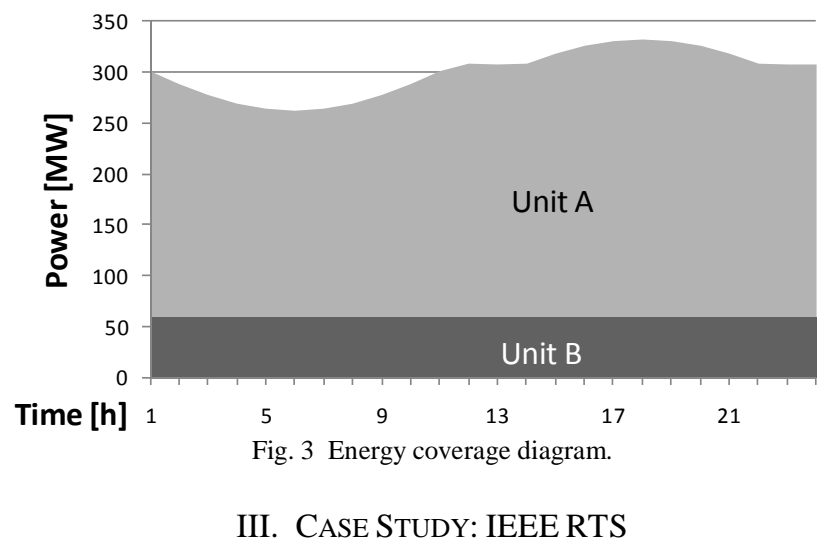

In this section, the proposed methodology is applied using an adapted version of the IEEE Reliability Test System (RTS96) [12] and hourly demand and wind power data for central Scotland in 2003 [13]. The optimization problem was solved using the Xpress optimization engine [14]. The effect of wind generation on the demand for the considered winter week is illustrated in Fig. 4. Here, wind power is considered 
deterministically, (i.e. modelled by just one profile) given that its variability is taken into account by the reserve constraint. A more formal approach would model wind stochastically. Using this renewable resource affects the demand and reduces the need for power from conventional generating units.

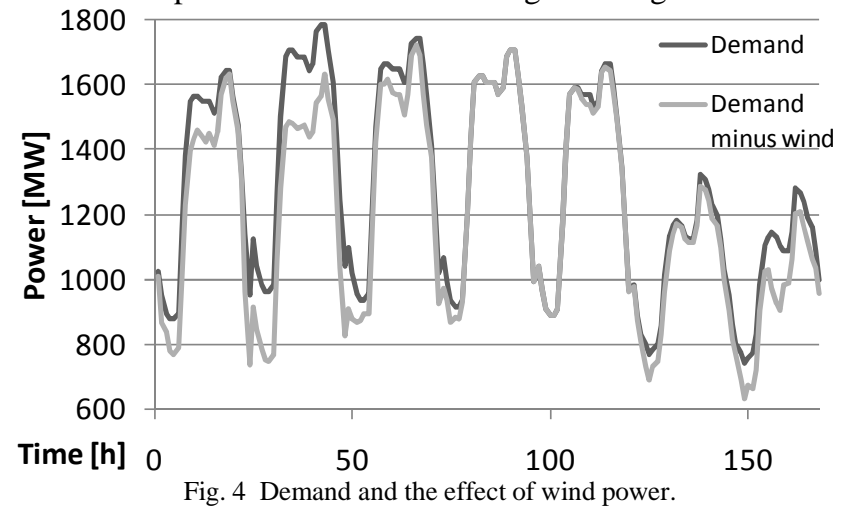

For this particular network it was assumed that a maximum $5 \%$ of the demand ) is available for demand side management, i.e. $\overline{D S M}(t)=0.05 * D(t)$. As the results will show, even such a relatively small fraction of the demand can have a significant impact on the optimal generation portfolio. Other penetration levels of DSM can also be considered [8].

Table III and table IV show respectively the economic and technical specifications of the generation portfolio considered for this case study. Units 1 to 9 are peaking units (low constraints on minimum up and down times, and large ramp rates) and units 24 to 26 are base units (lowest incremental costs).

TABLE III

PRODUCTION COSTS SIMPLIFIED RTS SYSTEM

\begin{tabular}{|c|c|c|c|c|c|c|c|c|c|c|}
\hline Unit & Technology & $\begin{array}{c}\text { Min } \\
\text { Power } \\
\text { (MW) }\end{array}$ & $\begin{array}{r}\text { Power } \\
\text { elbow1 } \\
\text { (MW) }\end{array}$ & $\begin{array}{l}\text { Power } \\
\text { elbow2 } \\
\text { (MW) }\end{array}$ & $\begin{array}{l}\text { Max } \\
\text { Power } \\
\text { (MW) }\end{array}$ & $\begin{array}{c}\text { inc. } \\
\text { Cost } 1 \\
\text { (\$/MW } \\
\text { ) }\end{array}$ & $\begin{array}{c}\text { inc. } \\
\text { Cost } 2 \\
(\$ / \mathrm{MW} \\
)\end{array}$ & $\begin{array}{c}\text { inc. } \\
\text { Cost } 3 \\
\text { (\$/MW } \\
\text { ) }\end{array}$ & $\begin{array}{c}\text { No } \\
\text { Load } \\
\text { Cost } \\
(\$)\end{array}$ & $\begin{array}{c}\text { Start } \\
\text { Up } \\
\text { Cost } \\
(\$)\end{array}$ \\
\hline $1-5$ & Fossil_Oil_1 & 2.4 & 5.6 & 8.8 & 12 & 25.75 & 25.91 & 26.07 & 24.0 & 68 \\
\hline $6-9$ & Combustible_Oil & 4 & 9.3 & 14.7 & 20 & 37.71 & 37.84 & 37.97 & 117.3 & 5 \\
\hline $10-13$ & Fossil_Coal_1 & 15.2 & 35.5 & 55.7 & 76 & 13.77 & 14.13 & 14.48 & 76.4 & 656 \\
\hline $14-16$ & Fossil_Oil_2 & 25 & 50 & 75 & 100 & 18.47 & 18.78 & 19.09 & 210.1 & 566 \\
\hline $17-20$ & Fossil_Coal_2 & 54.2 & 87.8 & 121.4 & 155 & 11.35 & 11.66 & 11.97 & 120.7 & 1048 \\
\hline $21-23$ & Fossil_Oil_3 & 69 & 111.6 & 154.3 & 197 & 23.47 & 23.69 & 23.91 & 239.2 & 775 \\
\hline 24 & Fossil_Coal_3 & 140 & 210 & 280 & 350 & 11.40 & 11.61 & 11.83 & 132.1 & 4468 \\
\hline $25-26$ & Nuclear_1 & 100 & $\overline{200}$ & 300 & 400 & 8.07 & 8.46 & 8.85 & 221.2 & 0 \\
\hline
\end{tabular}

TABLE IV

DYNAMIC PARAMETERS SIMPLIFIED RTS SYSTEM

\begin{tabular}{|c|c|c|c|c|c|c|}
\hline Unit & Technology & $\begin{array}{c}\text { Investment } \\
\text { Cost } \\
(\$ / M W)\end{array}$ & $\begin{array}{c}\text { Ramp Up } \\
(\mathrm{MW} / \mathrm{h})\end{array}$ & $\begin{array}{c}\text { Ramp } \\
\text { Down } \\
(\mathrm{MW} / \mathrm{h})\end{array}$ & $\begin{array}{c}\text { Minimum } \\
\text { time Up } \\
(\mathrm{h})\end{array}$ & $\begin{array}{c}\text { Minimum } \\
\text { time } \\
\text { down (h) }\end{array}$ \\
\hline $1-5$ & Fossil_Oil_1 & 214400 & 48 & 60 & 1 & 1 \\
\hline $6-9$ & Combustible_Oil & 272666 & 31 & 70 & 1 & 1 \\
\hline $10-13$ & Fossil_Coal_1 & 2923469 & 39 & 80 & 3 & 2 \\
\hline $14-16$ & Fossil_Oil_2 & 1786670 & 51 & 74 & 4 & 2 \\
\hline $17-20$ & Fossil_Coal_2 & 5962339 & 55 & 78 & 5 & 3 \\
\hline $21-23$ & Fossil_Oil_3 & 3519740 & 55 & 99 & 5 & 4 \\
\hline 24 & Fossil_Coal_3 & 13463345 & 70 & 220 & 8 & 5 \\
\hline $25-26$ & Nuclear_1 & 21170000 & 55 & 200 & 8 & 5 \\
\hline
\end{tabular}

Fig. 5 shows how demand is affected by the introduction of DSM. As expected, the final demand (demand with DSM) to be supplied by the conventional generators is flattened compared to the un-modified demand. This is particularly significant during peak periods. Since the proportion of available DSM capacity is not very high (5\%), the overall impact is (visually) relatively small.

Figure 6 shows that wind power moves the load duration curve down during the peak hours (Figure 6) and up during the off-peak hours (Figure 7).

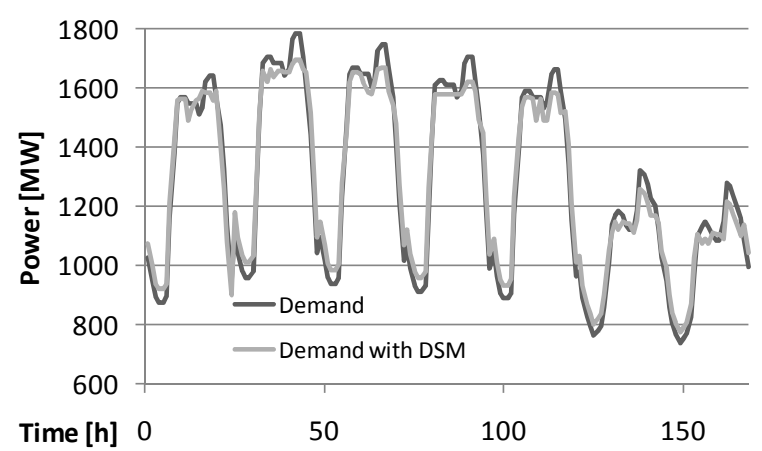

Fig. 5 Influence of DSM on demand to be fed by the generation portfolio.

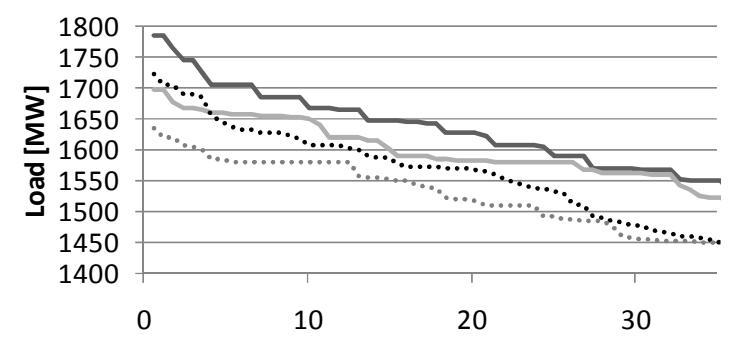

Fraction of hours of the year [h]

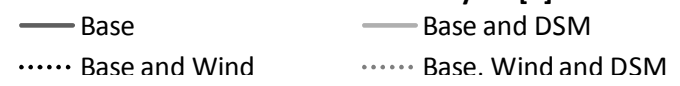

Fig. 6 Load duration curve - peak hours.

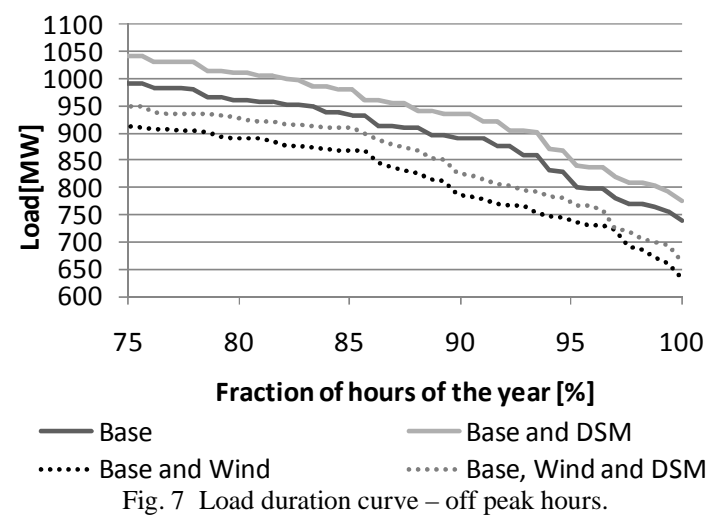

Table $\mathrm{V}$ shows the number of units of different types that would provide an optimal generation portfolio for the different scenarios considered. The introduction of DSM reduces the need for peaking units while the integration of wind power increases the need for such units. Fig. 8 gives the corresponding cost breakdown for all the studied cases. The obvious effect is that wind power reduces the demand and thus the overall operating costs. As mentioned earlier, the cost of investments in wind farms are not taken into account in this analysis. The introduction of DSM reduces both the operating and the investment costs for the base case and the case with wind generation. DSM has a marginal effect on the investment 
cost in the case with wind generation. However, the introduction of DSM reduces significantly the requirements of peaking units. In a sense, DSM is able to provide some of the flexibility that is usually provided by peaking units.

TABLE V

NUMBER OF GENERATING UNITS OF VARIOUS TYPES IN THE OPTIMAL GENERATION PORTFOLIO

\begin{tabular}{|c|c|c|c|c|}
\hline Unit types & $\begin{array}{c}\text { Base } \\
\text { Case }\end{array}$ & $\begin{array}{c}\text { Base \& } \\
\text { DSM }\end{array}$ & $\begin{array}{c}\text { Base \& } \\
\text { Wind }\end{array}$ & $\begin{array}{c}\text { Base, wind } \\
\& \text { DSM }\end{array}$ \\
\hline Peaking & 8 & 5 & 9 (all) & 6 \\
\hline Base & 3 & 3 & 3 & 3 \\
\hline Intermediate & 10 & 7 & 6 & 7 \\
\hline
\end{tabular}

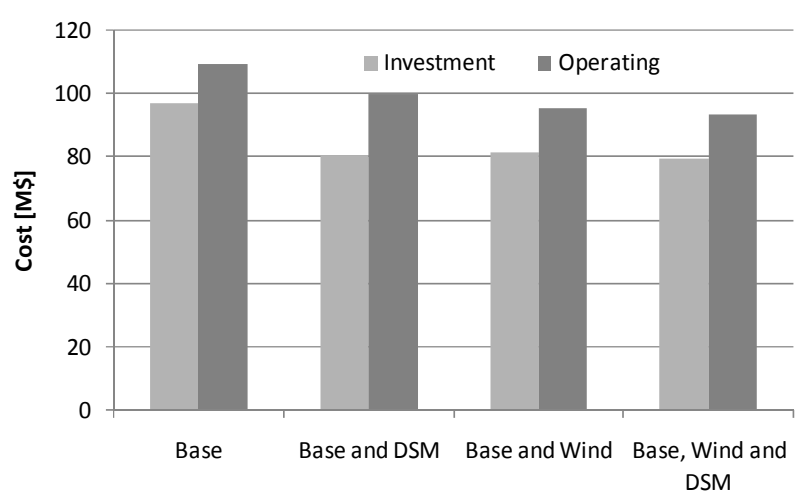

Fig. 8 Investment and generation costs for the various scenarios considered.

\section{CONCLUSIONS}

This paper has proposed an expanded methodology to consider both the short- and long-term operational and investment costs of providing flexibility. This technique is a powerful tool to analyze how demand-side management can be used to meet some of the requirements for flexibility in power systems. Results from its application to the simplified RTS system show that as wind is introduced in the generation mix, more flexibility is required. Provided the corresponding real-time monitoring and control infrastructure is in place, demand side management schemes, such as the aggregation of smart appliances, would not only improve the performance of the system but would also allow the integration of more renewable energy resources.

It is important to mention that since electricity is an essential good, DSM will be limited. Therefore, in the future, other sources of flexibility, such as storage, will also need to be part of the solution.

Further analyses should consider the stochasticity of wind generation, the uncertainty on the provision of reserve by the demand and the need for occasional load shedding. The study of other flexible resources such as interconnections with other systems and the introduction of storage will be considered in further work.

\section{REFERENCES}

[1] F. P. Sener, "System planning using existing flexibility," IEEE Trans. on Power Systems, vol. 11, no. 4, pp. 1874-1878, Nov. 1996.

[2] G. Xu, C. Kang, G. Yang, and Z. Wang, "A novel flexibility evaluating approach for power system planning under deregulated environment," in Proc. 2006 International Conference on Power System Technology (PowerCon), pp. 1-6.

[3] A. Tuohy, P. Meibom, E. Denny, and M. O'Malley, "Unit commitment for systems with significant wind penetration," IEEE Trans. on Power Systems, vol. 24, no. 2, pp. 592-601, May 2009.

[4] D. Kirschen, "Demand-side view of electricity markets," IEEE Trans. on Power Systems, vol. 18, no. 2, pp. 520-527, May 2003.

[5] G. Strbac, "Demand side management: Benefits and challenges," Energy Policy, vol. 36, no. 12, pp. 4419-4426, Dec. 2008.

[6] C.-L. Su and D. Kirschen, "Quantifying the effect of demand response on electricity markets," IEEE Trans. on Power Systems, vol. 24, no. 3, pp. 1199-1207, Aug. 2009.

[7] R. Tyagi, J. Black, and J. Petersen, "Scheduling demand response events with constraints on total number of events per year," in Proc. 2010 IEEE Energy Conversion Congress and Exposition (ECCE), pp. 1501-1504.

[8] A. Kowli and G. Gross, "Quantifying the variable effects of systems with demand response resources," in Proc. 2010 Bulk Power System Dynamics and Control Symposium (iREP).

[9] M. Akmal, D. Flynn, J. Kennedy, and B. Fox, "Flexible heat load for managing wind variability in the Irish power system," in Proc. 2009 International Universities Power Engineering Conference (UPEC).

[10] R. Sioshansi, "Evaluating the impacts of real-time pricing on the cost and value of wind generation," IEEE Trans. on Power Systems, vol. 25, no. 2, pp. 741-748, May 2010.

[11] D S Kirschen, J Ma, V Silva, R Belhomme, "Optimizing the Flexibility of a Portfolio of Generating Plants to Deal with Wind Generation" in Proceedings of the IEEE PES General Meeting, July 2011.

[12] C. Grigg, P. Wong, P. Albrecht, R. Allan, M. Bhavaraju, R. Billinton, Q. Chen, C. Fong, S. Haddad, S. Kuruganty, W. Li, R. Mukerji, D. Patton, N. Rau, D. Reppen, A. Schneider, M. Shahidehpour, and C. Singh, "The IEEE Reliability Test System-1996. A report prepared by the Reliability Test System Task Force of the Application of Probability Methods Subcommittee," IEEE Trans. on Power Systems, vol. 14, no. 3, pp. 1010-1020, Aug. 1999.

[13] T. Boehme, J. Taylor, A. R. Wallace, and J. W. Bialek, "Matching renewable electricity generation with demand," Scottish Executive, Edinburgh, Feb. 2006.

[14] Dash and Associates, "Modeling with Xpress-MP," 2005, Available: http://www.dashoptimization.com/home/downloads/pdf/Modeling_with Xpress-MP.pdf 